\title{
Therapeutic decision in adult patient with Bland-White- Garland Syndrome (ALCAPA)
}

\begin{abstract}
The present study reports the case of a 32-year-old-female patient, born in the city of Sao Paulo, Brazil, that underwent coronary angiography to investigate exercise intolerance and palpitations with positive test for myocardial ischemia in hemodynamics service in Real e Benemérita Associaçao Portuguesa de Beneficencia Sao Paulo-Sao Joaquim Hospital. During the hemodynamic examination she was diagnosed with Syndrome Bland-White-Garland, a rare congenital defect, estimating its incidence at 1: 300,000 live births. It was chosen to hospitalization for complementary tests and therapeutic decision. After detailed study of the case, we followed-up the patient with conservative treatment for 5 months with partial improvement of symptoms, but with myocardial scintigraphy showing drug induced ischemia, large to moderate extension, we indicated the surgical treatment. After 3 months, patient was asymptomatic with scintigraphy showing discreet extension of ischemia.
\end{abstract}

Keywords: ALCAPA syndrome; Bland-White-Garland syndrome; Coronary anomaly; Interventional cardiology; Congenital defect

\section{Introduction}

The Anomalous origin of the left coronary artery from the pulmonary artery (ALCAPA), known as Bland-White-Garland Syndrome, is a rare congenital defect (1:300,000 live births) which has high mortality rate in the first year and only $10-15 \%$ reach adulthood [1].

\section{Case Report}

A 32-year-old female, underwent coronary angiography to investigate exercise intolerance and palpitations with positive test for myocardial ischemia. Transthoracic echocardiogram showed ejection fraction of $69 \%$ without functional disorder.

Coronary angiography (Figure 1) showed a dilated right coronary irrigating the posterior side of the left ventricle, long and irregular left coronary trunk (LCT) coming out of the trunk of the pulmonary artery, right coronary artery with well-developed collateral circulation of the left coronary and the diagnose of ALCAPA was performed [2].

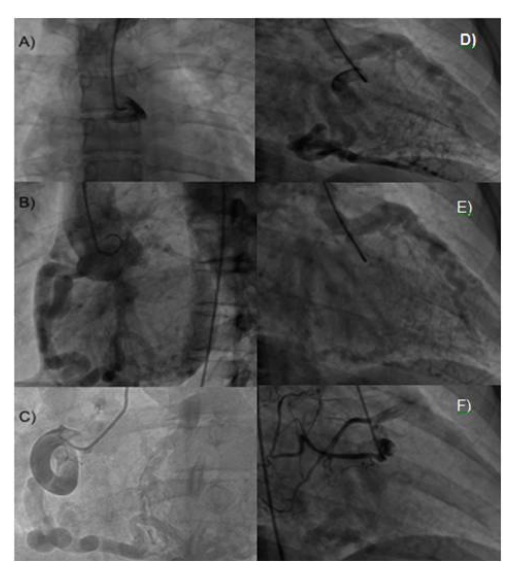

Figure 1: Coronary Angiography. A) Attempt to catheterize left coronary sinus; B) Right coronary artery with intense network side; C) Right Coronary Artery dilated; D) Right coronary and left coronary; E) Late filling left coronary; F) Right collateral.

A tomography of the coronary arteries (Figures 2 and 3) showed the anomalous origin of the LCT and all coronary anatomy adapted to the low oxygen blood. Asymptomatic after use of beta-blocker, the patient was discharged for clinical follow-up [3].
Thomas C Assmann *, Raphael Chiarini, David B Mattos, Leandro AF Nascimento, Marcos CV de Almeida,Januário M de Souza and Décio Salvadori Junior

Hospital Real e Benemérita Associação Portuguesa, de Beneficência, de São Paulo, Brazil

*Author for correspondence:

thomas89@gmail.com

Tel: +551637117777

Submitted: 15 January 2017

Accepted: 02 February 2017

Published online: 07 February 2017 


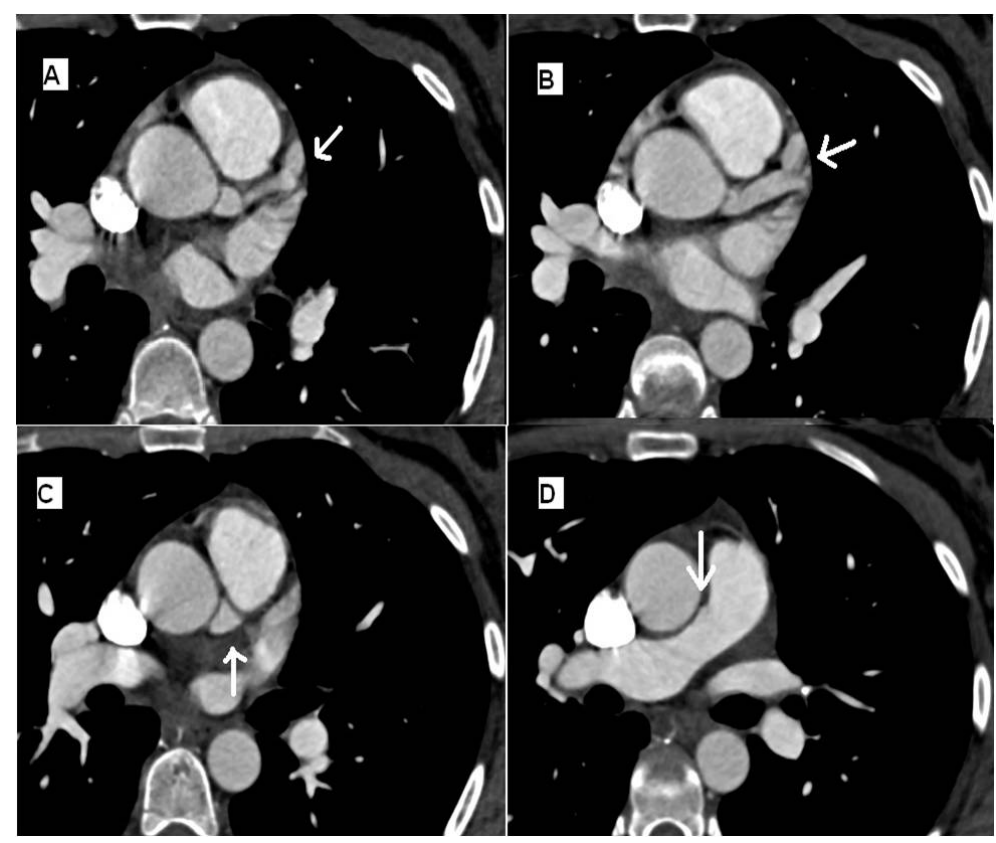

Figure 2: CTA. A) Left Coronary Trunk (arrow); B) Left coronary trunk (arrow); C) Proximal part Left Coronary Trunk (arrow); D) Left Coronary Trunk Origin pulmonary artery trunk.

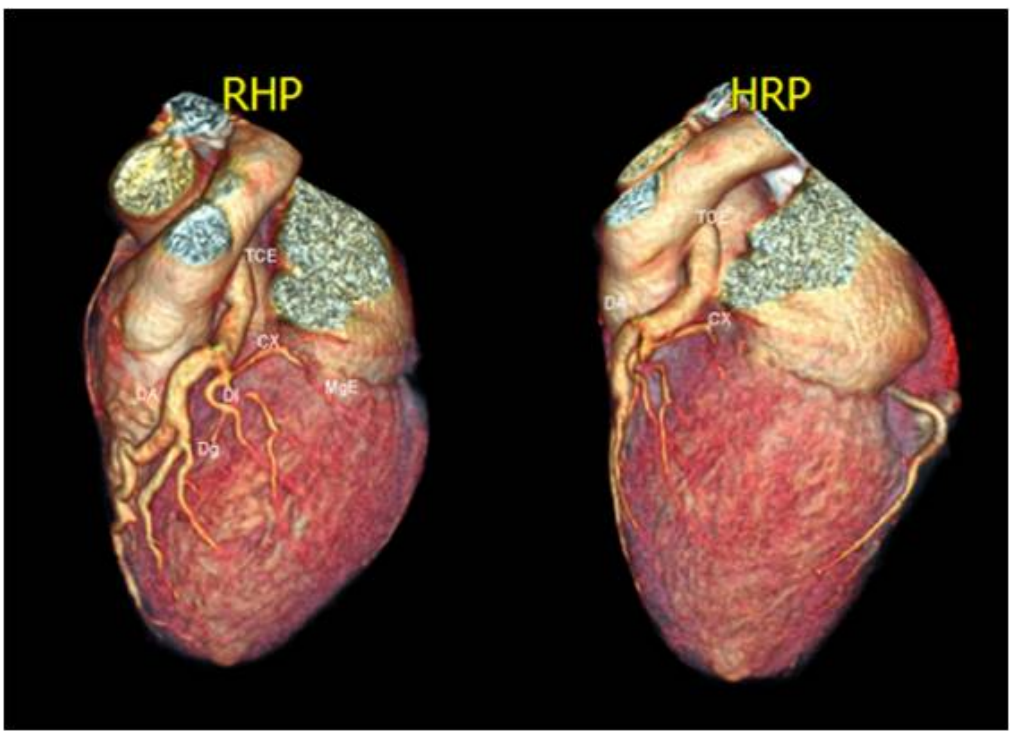

Figure 3: 3D reconstruction of coronary tomography. Translation of Portuguese abbreviation: TCE: Left main trunk. Cx: Left circumflex artery. Dg: Diagonal branch. MgE: Left marginal artery. DA: Left anterior descending.

On the third month of follow-up the patient begun to experience chest pain with exercises despite of the clinical treatment. The myocardial scintigraphy showed stress induced hypo perfusion of the ventricle's wall irrigated by the Anterior Descending coronary. Thus, the surgical treatment was indicated [4].

The surgical correction was the re-implantation of left coronary in the aorta. A bypass of the left internal thoracic artery to anterior descending artery was made to ensure the blood flow. After 3 months a new myocardial scintigraphy showed reduced ischemic area at rest and under stress, and reduction in symptomatology [5].

\section{Conclusion}

The clinical treatment was not sufficient to eliminate both symptoms and ischemia. On the other hand, surgical correction of the anomaly showed to be effective on reducing ischemia and symptoms.

sample 
Executive Summary

The present study reports the case of a 32-year-old-female patient, born in the city of Sao Paulo, Brazil, that underwent coronary angiography to investigate exercise intolerance and palpitations with positive test for myocardial ischemia in hemodynamic service in Real e Benemérita Associaçao Portuguesa de Beneficencia Sao Paulo-Sao Joaquim Hospital.

During the hemodynamic examination she was diagnosed with Syndrome Bland-White-Garland, a rare congenital defect, estimating its incidence at 1:300,000 live births. It was chosen to hospitalization for complementary tests and therapeutic decision.

After detailed study of the case, we followed-up the patient with conservative treatment for 5 months with partial improvement of symptoms, but with myocardial scintigraphy showing drug induced ischemia, large to moderate extension, we indicated the surgical treatment. After 3 months, patient was asymptomatic with scintigraphy showing discreet extension of ischemia.

\section{References}

1. Amaral F. Origem anômala da artéria coronária esquerda do tronco pulmonar: perfil clínico e resultados a médio prazo do tratamento cirúrgico. Arq. Bras. Cardiol. 72, 307-313 (1999).

2. Wesselhoft H, Fawcet JS, Johnson AL. Anomalous origin of the left coronary from the pulmonary trunk: its clinical spectrum, patology and pathophysiology, based on a review of 140 cases with seven further cases. Circulation. 38, 403-425 (1968).

3. Fierens C. A 72 year old woman with ALCAPA. Heart. 83, E2 (2000).

4. Barbetakis N. A long-term survivor of Bland-White-Garland syndrome with systemic collateral supply: a case report and review of the literature. BMC. Surg. 5, 23 (2005).

5. Jacob JL, Salis FV. Origem anômala da artéria coronária esquerda do tronco pulmonar em mulher de 45 anos. Arq. Bras. Cardiol. 81(2), 196-198 (2003). 